\title{
Experimental bearing capacity of eccentrically loaded foundation near a slope
}

https://doi.org/10.2478/sgem-2019-0004

received July 22, 2018; accepted January 15, 2019.

\begin{abstract}
Based on the response of small-scale model square footing, the present paper shows the results of an experimental bearing capacity of eccentrically loaded square footing, near a slope sand bed. To reach this aim, a steel model square footing of $(150 \mathrm{~mm} \times 150 \mathrm{~mm})$ and a varied sand relative density of $30 \%, 50 \%$ and $70 \%$ are used. The bearing capacity-settlement relationship of footing located at the edge of a slope and the effect of various parameters such as eccentricity (e) and dimensions report $(\mathrm{b} / \mathrm{B})$ were studied. Test results indicate that ultimate bearing capacity decreases with increasing load eccentricity to the core boundary of footing and that as far as the footing is distant from the crest, the bearing capacity increases. Furthermore, the results also prove that there is a clear proportional relation between relative densities -bearing capacity. The model test provides qualitative information on parameters influencing the bearing capacity of square footing. These tests can be used to check the bearing capacity estimated by the conventional methods.
\end{abstract}

Keywords: Square footing; bearing capacity; slope; relative density; eccentric load.

\section{Introduction}

The most important and pivotal part of any structure is the foundation. That's why, it is crucial to know the type of the soil, its behaviour, and bearing capacity. Several studies have led to a considerable progress as far as the understanding of 'the shallow foundation's behaviour under applied loads' is concerned. However,

\footnotetext{
*Corresponding author: Tarek Mansouri, Research Laboratory in Hydraulic Applied LARHA, Department of Civil Engineering, University of Batna 2, Algeria, E-mail: mansouritarek82@gmail.com Khelifa Abbeche: Research Laboratory in Hydraulic Applied LARHA, Department of Civil Engineering, University of Batna 2, Algeria
}

the conventional method of footing design requires ample security against breakdown. So, to reach the target goal, the bearing capacity of soil must be the main concern in any foundation design and the settlement has to be put up within the adequate frame. And bearing pressure on the underlying ground has to be kept within the safe allowable limit. Thus, the evaluation of load carrying capacity of the footing is an imperative step in foundation design. About the method of calculation, the literature reveals that the greater part of case studies has been based on a footing resting on a free soil of slope such as Ghosh and Kumar ${ }^{[9]}$ However, few studies have dealt with the case of the shallow foundation of diverse geometry based on a slope and exposed to a centric and vertical eccentric load. In the case of circular foundations under eccentric loading, Highter and Anders ${ }^{[2]}$ presented a graphical result to agree on the effective area. Which is defined as an equivalent area of footing that can be loaded centrally when a vertical load is applied at a location other than the centroid of footing or when a foundation is subjected to a centric load and momentum. Moreover, Meyerhof $^{[18]}$ and Vesic $^{[31]}$ recommended an equation to calculate the effective area in the circular footing. $\mathrm{Zhu}^{[32]}$ investigated the bearing capacity of ring footings on dense sand under vertical loads; he conducted a centrifuge modelling and numerical analysis of bearing capacity of ring foundations on sand. He established that for eccentrically loaded ring footings, the bearing capacity decreases with increase in load eccentricity. However, the behaviour of eccentrically loaded strip footing has been reported by numerous researchers such as Ramlot and Vandeperre, ${ }^{[26]}$ who illustrated the results of a model test with eccentrically loaded square and circular footings. Meyerhof ${ }^{[18]}$ reported that the average bearing capacity of a footing decreases parabolically with an increase in eccentricity. Prakash and Saran ${ }^{[23]}$ demonstrated an inclusive mathematical formulation to calculate the final bearing capacity and settlement for strip foundations in a cohesive soil subjected to eccentric loading. Purkayastha and Char ${ }^{[25]}$ carried out stability analysis of an eccentrically loaded strip foundation on sand and recommended a dwindling factor for calculating the bearing capacity of 
the eccentrically loaded footings. Mahiyar and Patel ${ }^{[17]}$ studied an angle shaped footing subjected to eccentric loading. Bushra and Rusul ${ }^{[6]}$ presented an experimental study to determine the bearing capacity of eccentrically loaded square foundation on compacted reinforced dune sand over gypseous soil. It was found that the bearing capacity increases to 2.5 to 3.0 times after replacement and reinforcement of gypseous soil. For eccentric loads, the load carrying capacity decreases with the increase of eccentricity value. Algin ${ }^{[1]}$ conducted the study on elastic settlement under eccentrically loaded rectangular surface footings on sand deposits. The analytical closedform solutions and the resulting influence factors were presented for estimating the elastic settlement under the eccentrically loaded footing. The equations are also developed for the theoretical cases where the location of incompressible soil layer is infinitely deep. Some investigations show that, in case of non-cohesive soils, the bearing capacity is always governed by foundation failure, while in the cohesive soil, the bearing capacity of the foundation is dictated by the stability of the slope. So, when a footing is put upon or near a slope, the bearing capacity of the footing may be considerably decreased compared with the same footing resting on the horizontal soil surface. The decrease depends on the place of footing with respect to the slope, the slope angle, and the properties of the supporting soil. In the study led by Krabbenhoft et al. ${ }^{[14]}$ Lower bound calculations based on the finite element method is used to determine the bearing capacity of a strip foundation subjected to an inclined, eccentric load on cohesionless soil with varying surcharges and with friction angles. The results are presented as charts for practical design and are contrasted with the recommendations given in eurocode7. Badakhshan and Noorzad $^{[3]}$ led an experimental study on the behaviours of eccentrically loaded circular footing supported on both unreinforced and reinforced sands with geogrid layers. Badakhshan and Noorzad ${ }^{[4]}$ proposed a simplified method for the prediction of ultimate bearing capacity of eccentrically loaded foundation on geogrid reinforced sand bed. They attempted to develop the reduction factors for eccentrically ultimate bearing capacity of circular and square footings resting on geogrid-reinforced sand. Laboratory test results demonstrate that the ultimate bearing capacity of circular footing decreases less with an increment of load eccentricity in comparison with the square footing in reinforced condition. Improvement index investigated that the contribution of reinforcement layers in enhancing the ultimate bearing capacity increases with the load eccentricity. By means of a numerical modelling based on the finite difference method, Khitas et al. ${ }^{[13]}$ studied the effect of the tensile strength of interface on the undrained bearing capacity of a strip footing and evaluated the reliability of the effective width method under eccentric loading. Results demonstrate that the effective width method is not reliable in the presence of the tensile strength at the interface. Ouahab et al. ${ }^{[21]}$ used the finite element code Plaxis to study the undrained bearing capacity of the eccentrically loaded strip footings on non-homogenous clay layers. A practical range of the rate of strength non-homogeneity, the soil layer thickness and the embedment was examined.

Many investigators hold diverse assumptions for the assessment of bearing capacity of shallow foundation on a slope or near slope. The method for bearing capacity estimation on the sloping ground was first proposed by Meyerhof, ${ }^{[18]}$ and later on, many researchers had contributed in this field.

In this paper, the methods available for the estimation of bearing capacity of shallow foundation on a slope and near slope are discussed.

Prandtl's ${ }^{[24]}$ significant work for bearing capacity theory, the punching failure mechanism for thick metals based on the theory of plasticity, had been developed by Terzaghi ${ }^{[29]}$ to estimate the bearing capacity of shallow foundations, in which the effects of soil internal angle friction, soil cohesion, and surcharge were superposed, resulting in the bearing capacity factors $\left(\mathrm{N}_{\mathrm{c}}, \mathrm{N}_{\mathrm{\gamma}}\right.$, and $\left.\mathrm{N}_{\mathrm{q}}\right)$ that are still used nowadays. Meyerhof ${ }^{[18,19,20]}$ extended and developed the Terzaghi's theory to better account for soil strength, footing size and shape, embedment, and slope. Vesic ${ }^{[31]}$ further expanded on the effects of shallow foundation shape on the ultimate bearing capacity. However, despite all the studies on the effects of foundation shape and depth on bearing capacity. There has been limited insight into the bearing capacity of footings adjacent to soils. Many investigations for the assessment of bearing capacity of shallow foundation on a slope or near the slope hold diverse assumptions.

The method for bearing capacity estimation on the sloping ground was first proposed by Meyerhof ${ }^{[19]}$ and later on, many researchers had contributed in this area. Meyerhof ${ }^{[19]}$ investigated the general failure mechanisms for bearing capacity for footings placed on purely cohesive soils adjacent to slopes, using an assumed failure mechanism based on the empirical observation from the model footing tests carried out by Peynircioglu. ${ }^{[22]}$ However, he acknowledges that the actual quantifiable results were not available to confirm his analytical approach. Kusakabe et al. ${ }^{[15]}$ presented a series of design charts with dimensionless factors showing a reduction in the bearing capacity compared with the conventional 
bearing capacity approach for the footings placed on the level ground for soils with cohesion and without. Kusakabe et al. ${ }^{[15]}$ assumed an infinite slope of homogeneous soil and presented the change in the bearing capacity with increasing distance from the crest compared with the footing width. Griffiths ${ }^{[11]}$ performed finite element analyses to determine the bearing capacity of slope soil and attained reasonable results, including some for footings adjacent to slopes, yet required significant computational effort to determine the bearing capacity factors and was subject to convergence issues, especially for $\mathrm{N}_{\mathrm{r}}$ Based on the limit equilibrium. Azzouz and Baligh $^{[2]}$ introduced a series of design charts for strip and square footings placed on slopes composed of cohesive soils, presenting a normalized increase in the bearing capacity for footings subject to a varied distance from the crest. Graham et al., ${ }^{[10]}$ based on the failure mechanism of Meyerhof, ${ }^{[19]}$ established an analytical approach to bearing capacity and stress distribution for footings placed on slopes for cohesionless soils that were validated by experimental results. Bowles ${ }^{[5]}$ provided a set of revised bearing capacity factors $\mathrm{N}_{\mathrm{c}}$ and $\mathrm{N}_{\mathrm{y}}$ values for slope soils based on an assumed failure mechanism similar to that from Terzaghi but for a limited set of strong values. Shields et al. ${ }^{[27]}$ presented the revised bearing capacity factors for footing bearing capacity on cohesionless slopes. Cure et al. ${ }^{[7]}$ explored the effect of the ultimate load of footings near slopes; they presented the outcome of both series of experimental and analytical studies performed with a centrally and eccentrically loaded surface of shallow model strip footing. The values of the ultimate load figured out from experimental tests were compared with values derived via an analytical explanation based on the limit equilibrium approach.

A few studies addressing the bearing capacity on purely cohesive, cohesionless or slope soils have added to the current understanding of bearing capacity on or adjacent to slopes. Georgiadis ${ }^{[8]}$ performed a series of finite element (FE) analyses observing the failure mechanism and bearing capacity associated with the spread footings placed at top slopes composed of purely cohesive soils. His comparison included varying slope height and footing placement. Mabrouki et al. ${ }^{[16]}$ through their bi-dimensional numerical analysis of shallow foundation rested near slope under inclined loading, focused on the numerical analysis of the bearing capacity for a strip footing near a cohesionless slope, and subjected to a centred inclined load, using the finite difference code (FLAC). The twofolds findings show: a normalized failure envelopes in two-dimensional loading plane and the influence of the load inclination and the position of the footing with respect to the slope on the bearing capacity. Shukla and Jakka ${ }^{[28]}$ presented the results of the finite element analyses of strip footing resting on stable slopes. A large amount of potential soil slopes with different footing depths were analysed. It was established that the critical setback distance increases with an increase in the internal friction angle of soil, the depth of the footing and the slope gradient. A regression equation is also developed to directly estimate the reduction in the bearing capacity of footings resting over the slope.

Throughout the bibliographical analysis done along with this research, it had been noticed that many researches have been conducted on the same issue. But, with diverse parameters: either in terms of form, eccentricity or reinforcement and so on. However, the actual study had combined three critical parameters, that are: the relative density variation $\left(\mathrm{D}_{\mathrm{r}}\right)$, eccentricity $(\mathrm{e})$, and footing position according to the crest slope all together.

The distinctiveness of the work may consist chiefly in the nature of the Algerian soil, precisely that of the region of Biskra. The rapid population expansion and urbanization in Algeria have led to enlarged building areas and the decrease of appropriate horizontal ground surface, which becomes challenging. For this reason, the bearing capacity and criterion for building structure are changing. So, it becomes a motivated impetus for Algerians, as never before, to exploit unwanted soils or sites with complex morphologies.

The overall objective of this work is to explore and determine the bearing capacity behaviour of eccentrically square footing loaded on a slope, and this for various eccentricities (e), dimensions reports (b/B) and relative densities on a sandy soil. To achieve this, a square model footing is tested in the laboratory under controlled conditions.

\section{Experimental apparatus}

The experimental model tests were conducted in a test box, having the inside dimensions of $1.60 \mathrm{~m} \times 0.60 \mathrm{~m}$ in plane and $0.60 \mathrm{~m}$ in depth. The test box is made of steel with the front wall made of thick transparent Plexiglass panels and supported directly with 8 wheels rolling on horizontal steel support beam as shown in Figure 1. These beams were firmly fixed on horizontal steel columns. The Plexiglass permits the slope inclination observation. And allows the sample to be seen during the preparation and the sand particles' deformations to be scrutinized during the testing. But, due to the effect of the sand's own weight pressure and the applied load, the plexiglass risks to 
break down; that's why, it has been reinforced with two steel columns. The tank box is built sufficiently rigid to maintain the plane strain conditions by minimizing the out of plane displacement. To ensure the rigidity and avoid the tank's deformation, thick steel plate had been used. The inside walls of the tank are polished smooth to reduce the friction with the sand as much as possible. The square footing model is made of steel with five holes for the sake of accommodating bearing balls were used. While the middle hole was made at the footing centre, the other four holes were respectively made one after the other with a space of $10 \mathrm{~mm}$ from the centre hole. The square footing is placed in the centre of the tank on the sand bed, as shown in Figure 3. The two ends of the footing plate were polished smooth to minimize the end friction effects. The load is transferred to the footing through a bearing ball, as shown in Figure 2.

\subsection{Soil Proprieties}

The source of the sand used in this research is the southeast of Algeria (Biskra, Liwa). It was a medium to coarse sand that was washed, dried and sorted by the size of the particles. The maximum and the minimum dry densities of the sand were measured and the corresponding values of the minimum and the maximum void ratio were calculated. The particles' size distribution was determined using the dry sieving method and the results are shown in Figure 4.

Table 1 summarizes the geotechnical properties of the tested sand. A series of direct shear tests were performed to evaluate the shear strength of the sand using the specimens prepared by dry tamping. The internal friction angle related to the same relative density used in the model tests was found to be $37^{\circ}$.

\subsection{Testing procedure}

The experimental program consists of carrying out 60 load bearing tests on square footing model placed at different locations adjacent to the slope. Each test has been done at least three times for ensuring the results. Using the following variables: dimensions report (b/B), eccentricity (e), and relative density $\left(D_{r}\right)$, the work aims to investigate the behaviour of the slope bearing capacity subjected to eccentric loads square foundation.

The test model was prepared by compacting the sand in layers, each of $100 \mathrm{~mm}$ thick up to $400 \mathrm{~mm}$ height. The

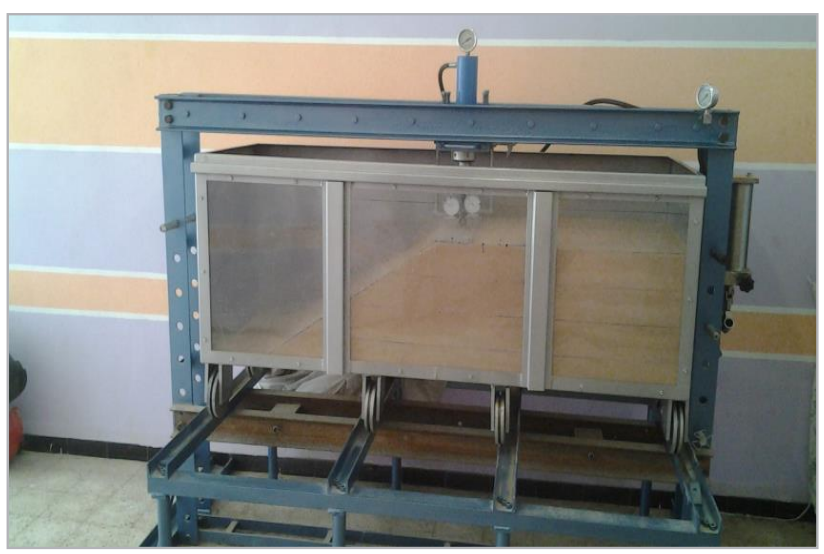

Figure 1: Experimental apparatus.

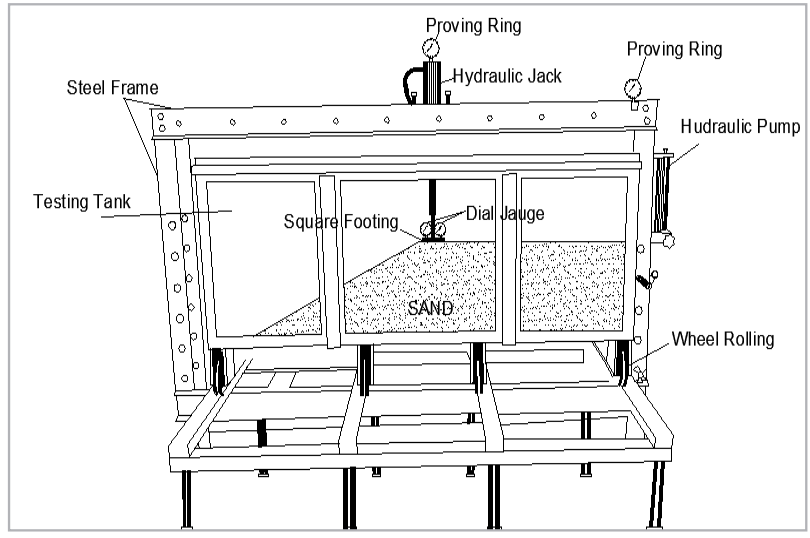

Figure 2: Vertical section of the model.

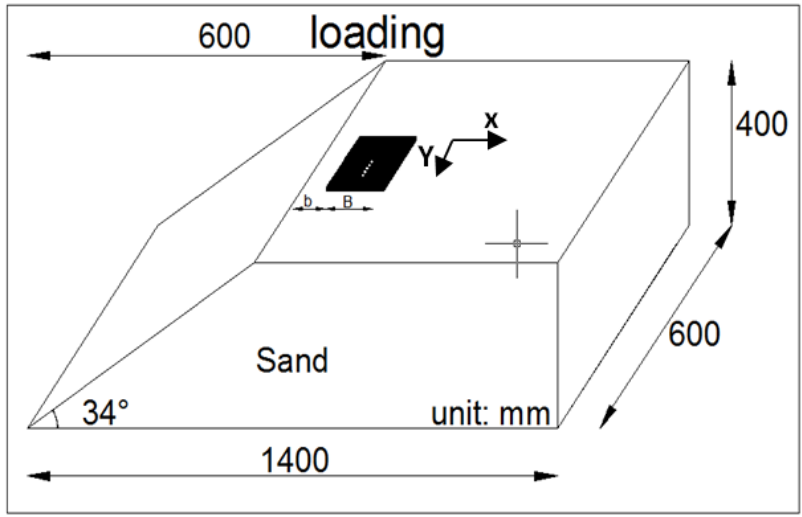

Figure 3: Geometry of the problem.

sand was compacted manually using a rammer of $200 \mathrm{~mm}$ in length, $150 \mathrm{~mm}$ in width and $5 \mathrm{~mm}$ in thickness, at a relative density of $30 \%, 50 \%$ and $70 \%$ according to the designed testing program, as shown in Table 2. The top surface of the formed sand was levelled using a sharpened 


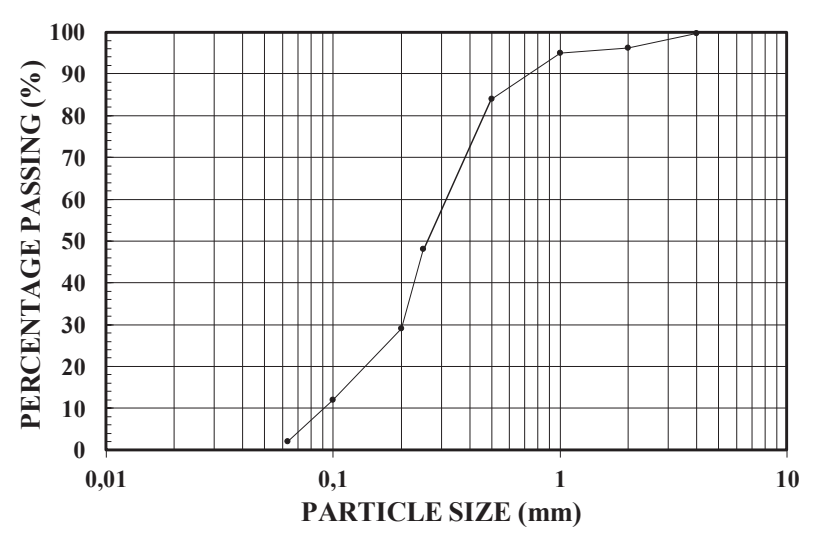

Figure 4: Grain size distribution curve of sand.

Table 1: Geotechnical properties of the tested sand.

\begin{tabular}{ll}
\hline Property & Value \\
\hline Coefficient of uniformity $\left(\mathrm{C}_{\mathrm{u}}\right)$ & 3.19 \\
Coefficient of curvature $\left(\mathrm{C}_{\mathrm{c}}\right)$ & 1.4 \\
Specific gravity $\left(\mathrm{G}_{\mathrm{s}}\right)$ & 2.65 \\
Maximum dry density $\mathrm{Y}_{\mathrm{d}} \max \left(\mathrm{KN} / \mathrm{m}^{3}\right)$ & 16.32 \\
Minimum dry density $\mathrm{Y}_{\mathrm{d}} \min \left(\mathrm{KN} / \mathrm{m}^{3}\right)$ & 14.31 \\
$\mathrm{D}_{60}(\mathrm{~mm})$ & 0.3 \\
$\mathrm{D}_{10}(\mathrm{~mm})$ & 0.094 \\
Maximum void ratio & 0.672 \\
Minimum void ratio & 0.551 \\
\hline
\end{tabular}

straight steel plate, and the model footing is then placed on the surface of the compacted sand. Reference markers on the Plexiglass side were used to form the required sand model. The model footing was placed on the top surface of the sand and the dial gauges were placed on the footing. After taking the zero loading, the load was applied in small increments and the dial gauges recorded the footing settlement at the end of each increment until failure.

\section{Results and discussions}

In order to probe the effect of both relative density and location of a footing to the slope crest (b/B), as well as to investigate the effect of the load eccentricity; a sequence of 60 tests had been carried out on a square model footing resting on loose, medium and dense sand slope. The ultimate Bearing capacity was gained by dividing the limit load to area of footing. For the present test results, the ultimate bearing capacity was determined by tangent
Table 2: Model tests program.

\begin{tabular}{llll}
\hline $\begin{array}{l}\text { Square footing } \\
(\mathrm{mm})\end{array}$ & $\begin{array}{l}\text { Sand relative } \\
\text { density } \\
\mathbf{D}_{\mathrm{r}}(\%)\end{array}$ & $\begin{array}{l}\text { Dimensions } \\
\text { report } \\
\mathbf{b} / \mathbf{B}\end{array}$ & $\begin{array}{l}\text { Eccentricity } \\
\mathbf{e}(\mathrm{mm})\end{array}$ \\
\hline $150 \times 150$ & 30 & 0 & $0,10,20,30,40$ \\
& 0.5 & $0,10,20,30,40$ \\
& 1 & $0,10,20,30,40$ \\
& & 1.5 & $0,10,20,30,40$ \\
& 0 & 0.5 & $0,10,20,30,40$ \\
& & 1 & $0,10,20,30,40$ \\
& & 1.5 & $0,10,20,30,40$ \\
& & 0 & $0,10,20,30,40$ \\
& & 0.5 & $0,10,20,30,40$ \\
& & 1 & $0,10,20,30,40$ \\
& & 1.5 & $0,10,20,30,40$ \\
\hline
\end{tabular}

intersection method Ueno et al., ${ }^{[30]}$ as shown in Figure 5; in the case of $(b / B=1, e=0)$. Load-settlement graphs have been draw.

The Figure 5 represents load-settlement variations for a varying relative density from $30 \%, 50 \%$ to $70 \%$. It is shows that a clear improvement in limit load from $1.41 \mathrm{kN}$, $2.1 \mathrm{kN}$ and $2.4 \mathrm{kN}$ had been achieved in the case

$\mathrm{e}=0, \mathrm{~b} / \mathrm{B}=0.5$. So, it can be deduced that with the increase in relative density of soil, the carry load of soil increases and equivalent settlements decreases, a fact that may be clarified by the close packing of soil grains with increase in its relative density. Also, by looking at the load-settlement graphs, it found that at relative densities of $30 \%, 50 \%$ and $70 \%$, soil had punching, local and general shear failure respectively.

Also, by looking at the load-settlement graphs, it found that at relative density of $30 \%$, soil had punching shear failure and the effect of slope is negligible. As seen in these graphs, an increase in the relative density modified the failure mechanism soil for local to general shear failure.

In order to evaluate the effect of the crest on the soil limit load, Figure 6 had been presented.

The tests of the first series were carried out on footings placed at the slope crest $(b / B=0)$, while the second series' tests were conducted on footings placed away at a distance (b/B $=0.5,1,1.5)$ from the slope crest.

The variations of the load-settlement for different footing position and the different relative densities are shown in Figure 6. 

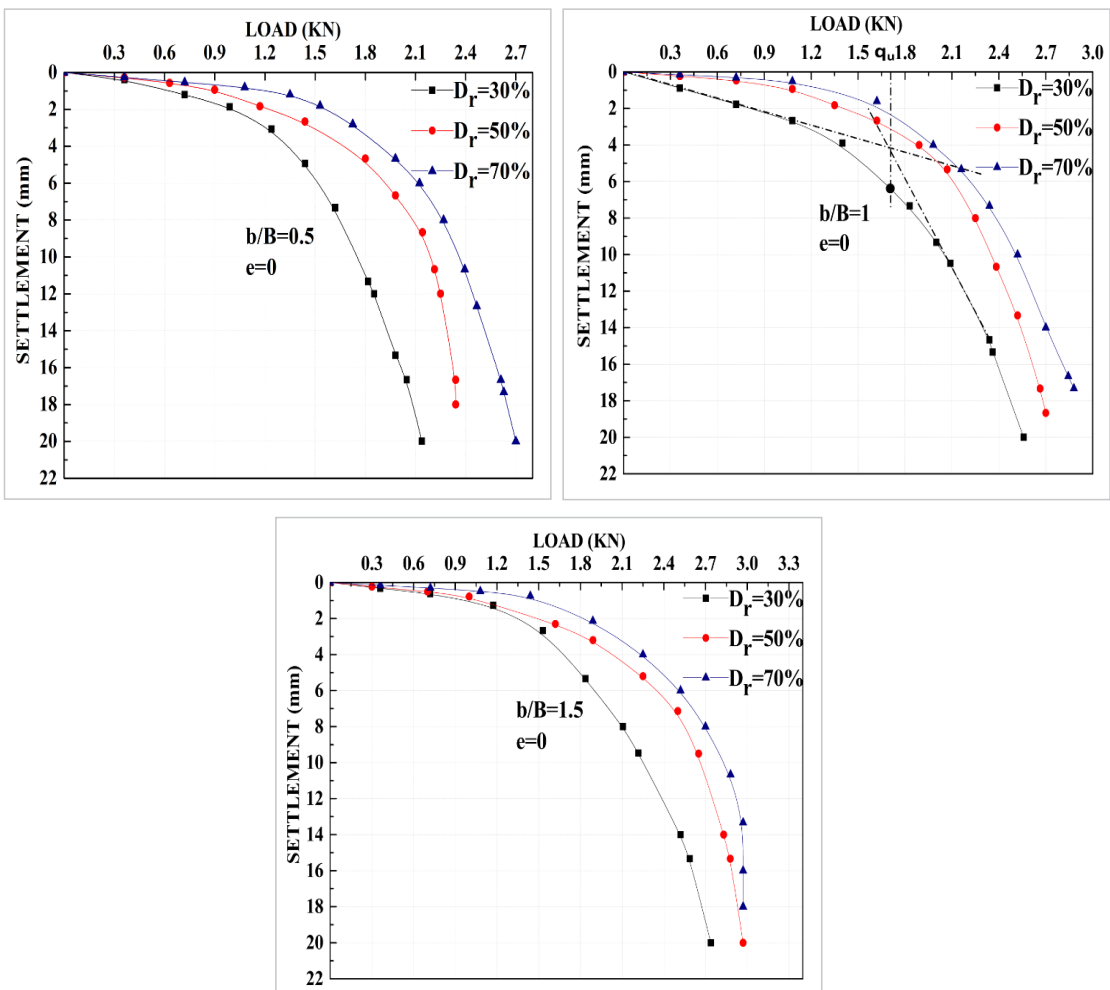

Figure 5: Variation of load with settlement for different case of relative density.
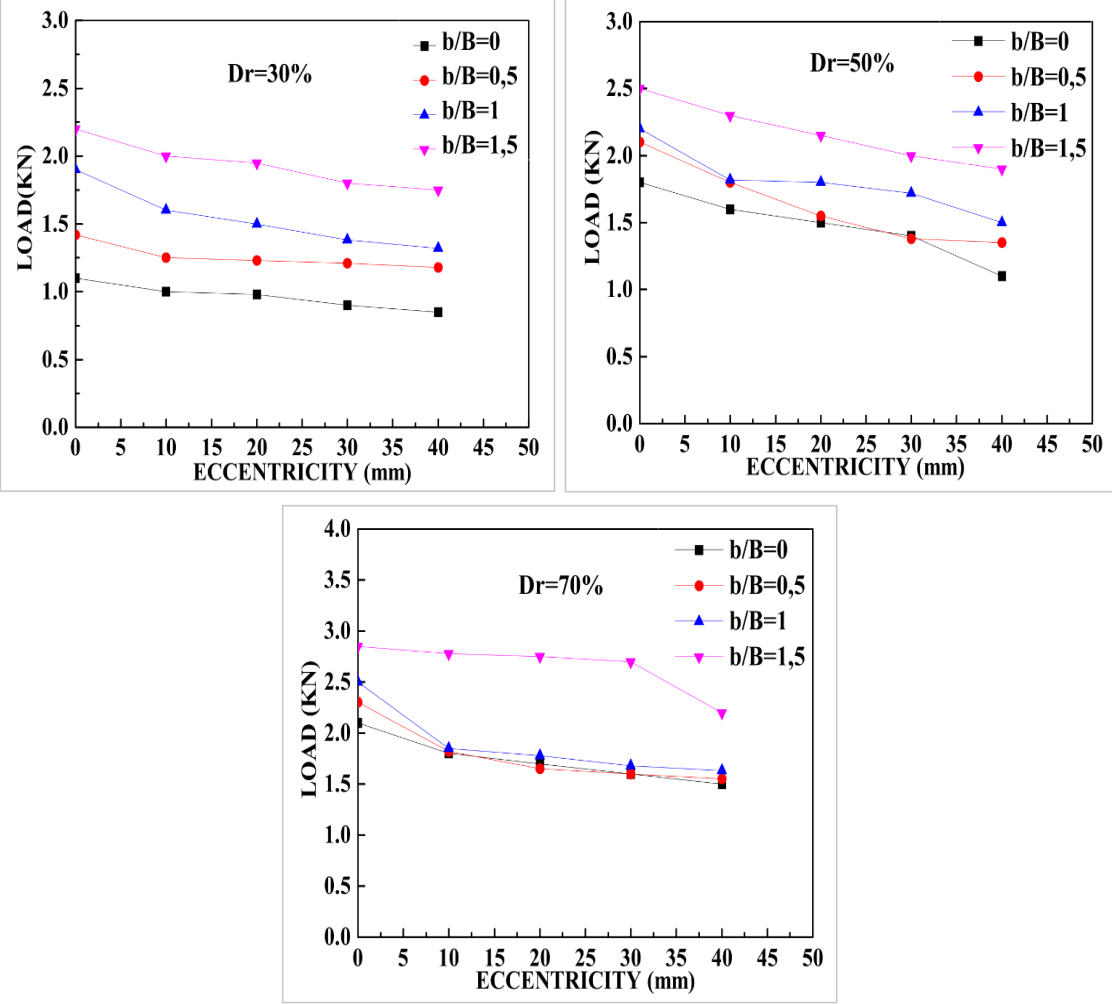

Figure 6: Load intensity with variable eccentricities for different relative densities of the footing on a slope 

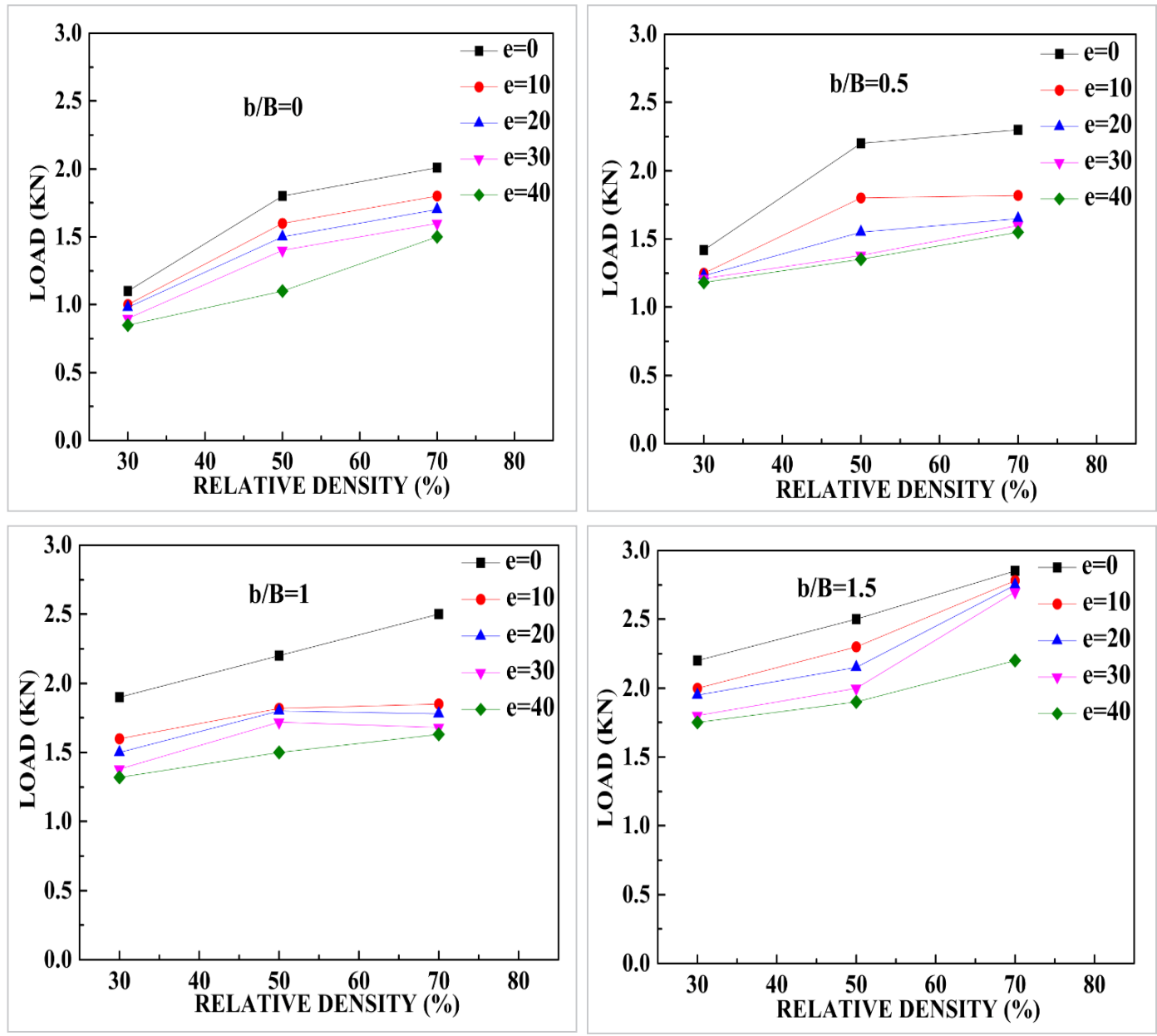

Figure 7: Load-relative density at different eccentricities for different state footing on a slope.

The results showed that the limit load for different relative densities of the footing on a slope system increases when the footing goes far from the crest of the slope (b/B $=0$ to 1.5) at variable eccentricities $(\mathrm{e}=0,10,20,30$ and $40 \mathrm{~mm})$. Also, it is shown clearly that the slope effect reduces at a distance ratio $(\mathrm{b} / \mathrm{B}=1.5)$ and the behaviour of the footing becomes almost comparable to that of footing situated on a horizontal soil.

According to the test results shown in Figure 7, the load-relative density curves have been plotted at different eccentricities varied from 0 to $40 \mathrm{~mm}$ at an increment of $10 \mathrm{~mm}$.

The limit load decreases with increasing load eccentricity to the core boundary of footing, and that as far as the footing is distant from the crest, the limit load increases. Also, the results prove that there is a clear proportional relation between relative densities - limit load.
For all the distance from the crest, the effect of relative densities is clearly shown in the case when the eccentricity value $\mathrm{e}=40 \mathrm{~mm}$.

The nature of decrease of limit load with an increase in eccentricity as observed from experimental results with those using Meyerhof. ${ }^{[18]}$

\section{Conclusions}

From the accomplished laboratory tests, the following may be concluded

- Load eccentricity significantly reduces the ultimate bearing capacity of square footing to the core boundary of footing.

- As increasing in relative density of soil, the carry load of soil increases and equivalent settlements decrease, a fact that may be clarified by the close packing of soil. 
- $\quad$ The bearing capacity increases when the distance of the foundation diverges from the slope.

- The displacement of the footings depends upon the applied load level, relative density of sand, and the load eccentricity.

- As eccentricity increases, the bearing capacity decreases.

- The curves clearly show that the cyclic settlements significantly increase as the footing locations move closer to the slope crest.

\section{References}

[1] Algin, H. M. \& Halil, M. (2009). Elastic settlement under eccentrically loaded rectangular surface footings on sand deposits. Journal of Geotechnical and Geoenvironmental Engineering .135.10, pp. 1499-1508.

[2] Azzouz, A. S. \& Baligh, M. M. (1983). Loaded areas on cohesive slopes. J. Geotech. Eng. 10.1061/ (ASCE) 07339410(1983)109:5(724), pp. 724-729.

[3] Badakhshan, E. \& Noorzad, A. (2015). Load eccentricity effects on behaviour of circular footings reinforced with geogrid sheets. Journal of Rock Mechanics and Geotechnical Engineering, 7(6), 691-699. https://doi.org/10.1016/j. jrmge.2015.08.006.

[4] Badakhshan, E. \& Noorzad, A. (2017). Effect of footing shape and load eccentricity on behaviour of geosynthetic reinforced sand bed. Geotextiles and Geomembranes volume 45, issue 2, pp. 58-67.

[5] Bowles, J. E. (1988). Foundation analysis and design. Mc GrawHill, New York. 4th ed.

[6] Bushra, S. A. \& Rusul, S. H. (2013). Bearing capacity of eccentrically loaded square foundation on compacted reinforced dune sand over gypseous soil. Paper presented at journal of earth sciences and geotechnical engineering, vol 3 , no. 4, pp. 47-62.

[7] Cure, E., Turker, E., \& Uzuner, B. A. (2014). Analytical and experimental study for ultimate loads of eccentrically loaded model strip footings near a sand slope. Ocean Engineering, 89, 113-118. https://doi.org/10.1016/j.oceaneng.2014.07.018.

[8] Georgiadis, K. (2010). Undrained bearing capacity of strip footings on slopes. J. Geotech. Eng. 10.1061 / (ASCE) GT.19435606.0000269 ,pp. 677-685.

[9] Ghosh, P. \& Kumar, J. (2005). Seismic bearing capacity of strip footings adjacent to slopes using the upper bound limit analysis. Electron.J.Geotech.Eng.10, bundle.

[10] Graham, J., Andrews, M. \& Shields, D. H. (1988). Stress characteristics for shallow footings in cohesionless slopes. Can. Geotech. J. 25(2), pp. 238-249.

[11] Griffiths, D. V. (1982). Computation of bearing capacity factors using finite elements. Geotechnique, 32(3), pp. 105-202.

[12] Highter, W.H. \& ANDERS, J.C. (1985). Dimensioning footings subjected to eccentric loads. ASCE Journal of Geotechnical Engineering, 111, No. 5 pp. 659-665.

[13] Khitas, N. E. H., Benmeddour, D., Mellas, M. \& Mabrouki, A. (2017). The undrained bearing capacity of strip footings under eccentric loading: effect of soil-footing interface tensile strength. International Journal of Geotechnical Engineering, 1-7. https://doi.org/10.1080/19386362.2017.1416570.

[14] Krabbenhoft, S., Damkilde, L. \& Krabbenhoft, K. (2014). Bearing capacity of strip footings in cohesionless soil subject to eccentric and inclined loads. International Journal of Geomechanics, 14(3), 04014003. https://doi.org/10.1061/ (asce)gm.1943-5622.0000332.

[15] Kusakabe, O., Kimura, T. \& Yamaguchi, H. (1981). Bearing capacity of slopes under strip loads on the top surfaces. Soils Found. 21(4), pp. 29-40.

[16] Mabrouki, A. \& al. (2016). 2D numerical analysis of shallow foundation rested near slope under inclined loading. Procedia Engineering volume 143, pp. 623-634.

[17] Mahiyar, H. \& Patel, A. N. (2000). Analysis of angle shaped footing under eccentric loading.

J.Geotech. Geoenviron. Eng. 10.1061/ (ASCE) 10900241(2000)126:12(1151), pp. 1151-1156.

[18] Meyerhof, G.G. (1953). The bearing capacity of foundations under eccentric and inclined loads. In proc. of the 3rd Int. Conf, on SMFE .vol 1. pp. 440-445.

[19] Meyerhof, G. G. (1957). The ultimate bearing capacity of foundations on slopes. ," Proceedings of the 4th Int. conf. S.M.F.E., vol. 3, pp. 384-386.

[20] Meyerhof, G. G. (1963). Some recent research on the bearing capacity of foundations. Canadian Geotechnical Journal, vol. I, No. 1, pp. 16-26.

[21] Ouahab, M. Y., Mabrouki, A., Mellas, M., \& Benmeddour, D. (2018). Effect of load eccentricity on the bearing capacity of strip footings on non-homogenous clay overlying bedrock. Transportation Infrastructure Geotechnology, 5(2), 169-186. https://doi.org/10.1007/s40515-018-0055-0.

[22] Peynircioglu, H. (1948). Tests on bearing capacity of shallow foundations horizontal top surfaces of sand fills and the behaviour of soils under such foundations. Proc., 2nd Int. Conf. On soil mechanics and foundation engineering, Rotterdam, Netherlands, pp. 144-205.

[23] Prakash, S. \& Saran, S. (1971). Bearing capacity of eccentrically loaded footings. Journal of SM \& FE division, ASCE 97, pp. 901-921.

[24] Prandtl, G. (1921). Eindringen steifigkeit und festigkeit von schneiden, Angew. Math. U. Mech.1, 15.

[25] Purkayastha, R. D. \& Char, R. A. (1977). Stability analysis for eccentrically loaded footings. J. Geotech. Eng. 103(6), pp. 647-651.

[26] Ramlot, C. \& Vandeperre, L. (1950). Electric pylons of foundations: Their resistance to overturning their stability, their calculation. Research rep. 2, IRSIA, France.

[27] Shields, D., Neil, C. \& Jacques, G. (1990). Bearing capacity of foundations in slopes. J. Geotech. Eng. 10.1061/ (ASCE) 07339410(1990)116:3(528), pp. 528-537.

[28] Shukla, R. P. \& Jakka, R. S. (2017). Critical setback distance for a footing resting on slopes. Acta Geotechnica Slovenica.

[29] Terzaghi, K. (1943). Theoretical soil mechanics. Wiley and sons Inc New York, 5th ed.

[30] Ueno, K., Miura, K. \& Maeda, Y. (1998). Prediction of ultimate bearing capacity of surface footing with regard to size effects. Soils found .38(3), pp. 165-178.

[31] Vesic, A.S. (1973b). Analysis of ultimate loads of shallow foundations. J. Soil mech. Found.Div, ASCE 99, No. SM1, 45-73. 
[32] Zhu, F. (1998). Centrifuge modelling and numerical analysis of bearing capacity of ring foundations on sand. Facdty of engineering and applied science Mernorial university of new foundland. 